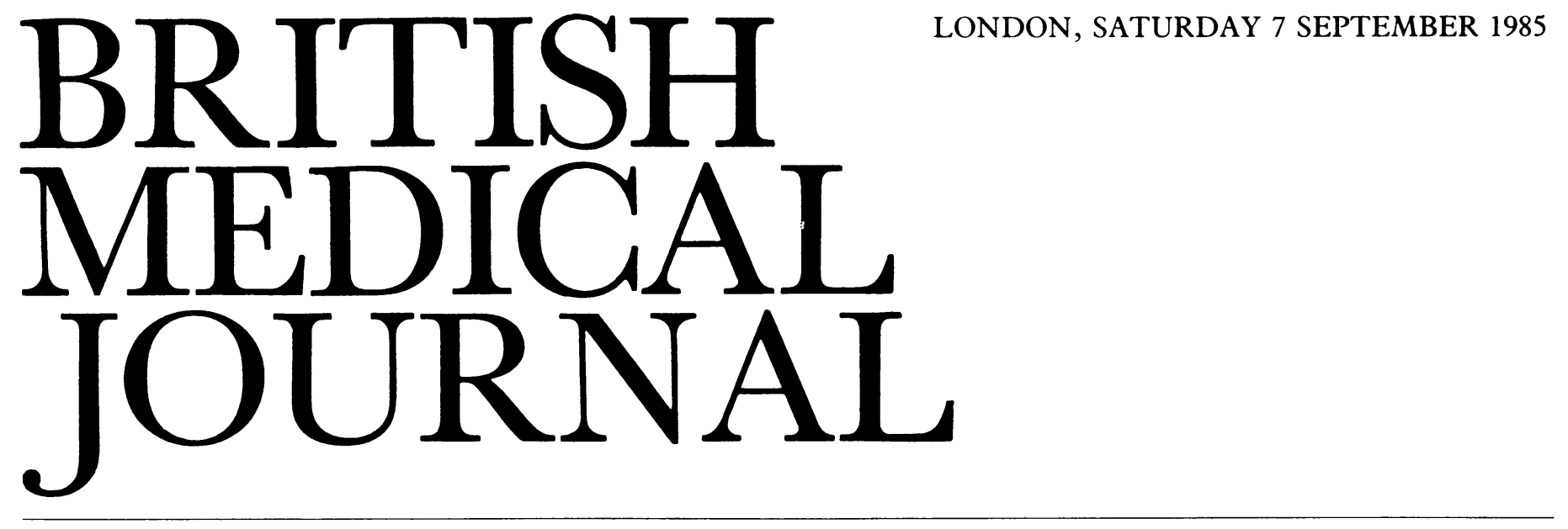

Artificial insemination by donor

Artificial insemination by donor (AID) is widely used to help infertile couples, ${ }^{1-4}$ but its success rates are difficult to assess because there is no uniform way of reporting results. ${ }^{6}$ The main indication for AID is azoospermia or severe oligozoospermia in the husband. Its use is more controversial when the couple have unexplained infertility. ${ }^{7}$ More recently the picture has been further confused by the use of in vitro fertilisation for couples in whom the husband has a very low sperm density. ${ }^{8}$

A recent report from Nottingham described four years' experience in a National Health Service AID clinic. ${ }^{1}$ Two hundred and seventeen women started treatment. Thirty four stopped early, 75 conceptions occurred in 65 women, and 118 women continued with inseminations. The average number of inseminations in the successful group was $12 \cdot 5$. A better chance of conception was reported in patients from social class I, those in the age range 20-25, and those not receiving treatment to induce ovulation. Female births predominated, confirming previous reports ${ }^{2} 9$ and in contrast with the expectation from natural conception. ${ }^{10}$ This discrepancy may result from successful insemination occurring before rather than after the apparent day of ovulation, but it may also be an effect of cryopreservation of sperm. ${ }^{9}$ The better chance of conception from younger wives has been reported previously. ${ }^{+11}$ Other important prognostic factors are the timing of the insemination in relation to the day of ovulation, whether fresh sperm or sperm stored in liquid nitrogen is used, and the numbers of motile sperm inseminated. ${ }^{4}$

If the results of AID are to be measured against the natural expectation of conception and the results of other treatments, including in vitro fertilisation, then careful statistical analysis is needed. Unfortunately, survival methods of statistical analysis were not used for the Nottingham series, and the conclusions might be erroneous if the recruitment rates from the different prognostic groups were not steady with time. ${ }^{1}$ Methods that could be used include the fecundability rating (conception rate per month) or fecundity rating (conception rate per cycle), as used in population demographic studies. $^{5612}$ The peak fecundity expected from normal couples having regular intercourse and at an age when conception is at its maximum is $25-27 \% .^{4}{ }^{12}$ For a large population irrespective of age the fecundability rate for the first two years after stopping contraception has been estimated at between $10 \%$ and $20 \% .^{13}$ In couples in whom the woman appears normal after investigations but the man has reduced sperm density the fecundability ranges from $0 \cdot 2 \%$ for wives with azoospermic husbands to a maximum of $5 \cdot 3 \%$ when the husband has between two and 10 million motile sperm $/ \mathrm{ml}$ (my unpublished data). Fecundity rates of $15 \%$ to $20 \%$ have been achieved in AID clinics using frozen semen. ${ }^{52}$ These rates approach those from the normal population and are certainly much greater than from couples with a problem in the husband. All this amounts to good evidence that AID is effective.

How, then, should an AID service be organised, and which couples should receive this form of help? Until now selection for AID has been haphazard-largely because data about the natural expectation of fertility in relation to the husband's semen have only recently become available. ${ }^{14}$ Infertility has often been attributed to the husband's poor sperm count with problems with ovulation coming to light only in the AID clinic after monitoring the menstrual cycle with ultrasound scanning or short hormone assays (methods used to time the insemination). Some couples may be identified in whom the husband has impaired spermatogenesis, in whom the chance of pregnancy is remote. ${ }^{7}$ Furthermore, the Nottingham series also identified women who will do well from insemination-those who are younger, of social class I or II, and who show spontaneous ovulation.' When all these requirements are met monitoring of ovulation seems unnecessary; so long as adequate donor samples can be supplied these couples could carry out their own inseminations. In our own hospital nine pregnancies were recorded from 27 women during 1984 who carried out their own "do it yourself" inseminations with an insulin syringe using samples from our liquid nitrogen sperm bank, which we supplied on demand. Medical and nursing staff were present only at the initial teaching session. Entry to this programme was restricted to couples who had been investigated in our infertility clinic and who therefore knew us. This pilot programme has shown the practicability of low cost "do it yourself" insemination, and if further selection is undertaken using the Nottingham data the success rate may approach that from natural conception.

The most important requirement for a successful AID programme is a plentiful supply of donor semen of good quality. Here in Britain we have not tackled the problem of finding enough donors, and each clinic has had to make its own ad hoc arrangements. These vary from paying donors 
from the pharmacy budget, using donor recruitment staff, or running a simple cash box system and asking recipients to contribute. In France central donor banks have been established, and samples are distributed to AID centres. ${ }^{15}$ The French system has the advantage that uniform standards may be applied, hazards monitored, and the number of pregnancies from any one donor restricted. In France one donor could not give samples to two different hospitals-as could happen in some of the larger British cities. There is no evidence of damage to the deoxyribonucleic acid or of teratogenicity from the use of donor or frozen donor semen $^{11}{ }^{16}$; the main risk to the recipient seems to be transmissible disease. At present donated samples cannot be guaranteed to be free from venereal disease, for with current resources it is not practicable to test each sample. This would be another advantage of a centralised recruitment centre.

Couples may now be told, then, that the rates of conception from AID approach those from natural conception. Now that prognostic factors have been identified some couples may be selected for "do it yourself," low cost AID schemes so that medical efforts may be concentrated on those who fail and those who have poor prognostic factors. The place of AID in the management of male infertility may, however, require reappraisal if the preliminary results of in vitro fertilisation for male infertility are confirmed from life table methods of analysis.

T B HARGREAVE

Senior Lecturer in Urology,
Western General Hospital,

Western General Hospi

1 Ledward RS, Symonds EM, Mountford PJ. Prognostic factors and results of successful donor insemination. Fournal of Obstetrics and Gynaecology in press?.

2 Newall R. AID, a review of 200 cases. Br f Lrol 1976;58:239-44.

2 Newall R. AID, a review of 200 cases. Br $\mathcal{F}$ Lrol 1976:58:239-44.
3 Trounson AO, Mathews CD, Kovacs GT. Artificial insemination by frozen donor semen: results of multicenter Australian experience. Int $\mathcal{F}$ Androl 1981;4:227-34.

4 Albrecht BH, Cramer D, Schiff I. Factors influencing the success of artificial insemination. Fertil Steril 1982;6:792-7.

5 Kerin J. Determination of the optimal timing of insemination in women. In: Richardson D. Joyce D, Symonds M, eds. Frozen human semen. Proceedings of workshop upon the cryobiology of human semen and its role in artificial insemination by donor. London: Royal College of Obstetricians and Gynaecologists, 1979:105-28

6 Mudge TJ. Updates in brief-the concept of fecundity. Clinical Reproduction and Fertility 1982:1:331-40.

lempleton A, Triseliotis J. AID and adoption. In: Hargreave TB, ed. Male infertility. Berlin Springer-Verlag, 1983:309-20.

Cohen J, Fehilly CH, Fishel SB, et al. Male infertility successfully treated by in vitro fertilisation. Lance 1984; : 1239

9 Mortimer D, Richardson DW. Sex ratio of births resulting from artificial insemination. $\mathrm{Br} f$ Obstet (innaecol 1982;89:132-5

10 Office of Population Censuses and Surveys. Lave hirths sex ratios 1841-1981. London: HMSO, 1983.

11 Virro MR, Shewchuk AB. Pregnancy outcome in 242 conceptions after artificial insemination with donor sperm and the effects of maternal age on the prognosis for successful pregnancy. Am $\mathcal{f}$ Oh:tet Ginecol 1984:148:518-24

12 Peck JC. Godfrey B, Matthews CD. Estimation of fertility and fecundity in women receiving artificial insemination by donor semen and in normal fertile women. Br. 7 Obstet (jynaecol $1984: 91: 1019-24$.

13 Smith SK, Cooke I. Infertility series: the role of the general practitioner. Brtish foumal of Sexual Medicine 1985:12:35-8

14 Hargreave TB, Elton RA. Is conventional sperm analysis of any use? Br f Urol 1983;55:774-9.

15 Schwartz D, Mayaux MJ, Boyce AM. Czyglik F, David G. Donor insemination: conception rate according to cycle day in a series of 821 cycles with single insemination. Fertil Steril 1979;31:226-9.

16 Richardson DW. Factors influencing the fertility of frozen semen. In: Richardson D, Joyce D, Symonds M, eds. Frozen human semen. Proceedings of a workshop upon the cryobiology of human Symonds $\mathrm{M}$, eds. Frozen human semen. Proceedings of a workshop upon the crvobiology of human
semen and its role in artificial insemination by donor. London: Royal College of Obstetricians and semen and its role in artificial inse
Gynaecologists, 1979:33-54.

\section{Hospital clinical records}

In the $B M \mathcal{F}$ of 26 January (p 263) we asked the question "Why keep hospital clinical records?" and listed five possible options. Hospital clinical records could be kept in their original format; they could be sampled or selected; they could be microfilmed; they could be destroyed after a certain period of time; or they could be kept, sampled, microfilmed, or destroyed according to local initiative. In the correspond- ence after the leader two more options emerged; patients might keep their own records, or rigorous file keeping would do much to solve the problem. Perhaps the original question should have been "What should we do with hospital clinical records?"

We thought that both questions could best be answered by those experienced in the subject, and this spring invited participants attended a symposium at the King's Fund Centre to examine the issues (the full papers and proceedings of the meeting are to be published by the centre this month). Inevitably there emerged no immediate answers: it would have been unrealistic to expect any, but the problems were seen clearly, a valuable exchange of information took place, and areas of agreement were exposed.

Clinical records fall into two distinct types: the bound volumes of older records and the case files gradually introduced in the 1920s and 1930s. Many features are common to both. The main problem is bulk. Some district health authorities have appointed archivists, and some county record offices take in the material, but often only up to 1900 . Such records take up a great deal of space, and many archivists simply have no room. The fact that the records are closed for 100 years is probably a deterrent. In hospitals the conditions in which many of these volumes are kept are often very poor-in cellars liable to flooding and alarmingly filthy.

Modern case files are not usually held in such bad conditions, but the problem of bulk is magnified many times over. Very few local record offices would be willing to take in modern case files. Many hospitals destroy them after the recommended retention time for possible use in litigation. Others are microfilming-but, though microfilming might satisfy the epidemiologists, unless the microfilm is kept in archival conditions it will not last. Even in archival conditions its lifetime is not certain.

The meeting discussed the question of confidentiality, and mention was made of the successful system in operation for some years at a mental health centre in Manchester which enabled patients to discuss and see their records at any time. Ultimately the issue of confidentiality may be seen in terms of etiquette. The 100 year closure period for clinical records, now generally accepted, was laid down in 1961, 'though hospital authorities have a discretion to make records available at an earlier date for research. ${ }^{2}$ Throughout the day, indeed, the importance of the records for research was recognised, although the needs of the historical researcher, the clinician, and the epidemiologist were seen to differ.

Speakers acknowledged that the overwhelming bulk of the records meant that they could not all be kept. One possibility was the establishment of a medical records centre as a final safety net, but this was seen as a less satisfactory solution than the appointment of archivists by regional authorities. In Scotland only a minority of the health boards have appointed archivists, and only on an ad hoc basis. The Wilson committee recommended the appointment of specified record officers for each regional health authority, ${ }^{3}$ but this recommendation was not accepted by the government. ${ }^{4}$

Some kind of sample or selection appears inevitable. How might this be achieved? Should there be a statistical sample? This might satisfy the historian but not the medical researcher. Should a selection be made on a regional basis? The meeting felt that there were strong reasons for seeing the selection or sample of records in three chronological divisions: the older volumes, the modern case file, and the future. Criteria for saving the older volumes might be bulk, type, and quality of the records, combined with the presence 